\title{
Ivermectin: enigmatic multifaceted 'wonder' drug continues to surprise and exceed expectations
}

\begin{abstract}
Andy Crump
Over the past decade, the global scientific community have begun to recognize the unmatched value of an extraordinary drug, ivermectin, that originates from a single microbe unearthed from soil in Japan. Work on ivermectin has seen its discoverer, Satoshi Ōmura, of Tokyo's prestigious Kitasato Institute, receive the 2014 Gairdner Global Health Award and the 2015 Nobel Prize in Physiology or Medicine, which he shared with a collaborating partner in the discovery and development of the drug, William Campbell of Merck \& Co. Incorporated. Today, ivermectin is continuing to surprise and excite scientists, offering more and more promise to help improve global public health by treating a diverse range of diseases, with its unexpected potential as an antibacterial, antiviral and anti-cancer agent being particularly extraordinary.
\end{abstract}

The Journal of Antibiotics (2017) 70, 495-505; doi:10.1038/ja.2017.11; published online 15 February 2017

\section{INTRODUCTION}

The unique and extraordinary microorganism that produces the avermectins (from which ivermectin is derived) was discovered by Ōmura in 1973 (Figure 1). It was sent to Merck laboratories to be run through a specialized screen for anthelmintics in 1974 and the avermectins were found and named in 1975. The safer and more effective derivative, ivermectin, was subsequently commercialized, entering the veterinary, agricultural and aquaculture markets in 1981. The drug's potential in human health was confirmed a few years later and it was registered in 1987 and immediately provided free of charge (branded as Mectizan)_-'as much as needed for as long as needed'-with the goal of helping to control Onchocerciasis (also known as River Blindness) among poverty-stricken populations throughout the tropics. Uses of donated ivermectin to tackle other so-called 'neglected tropical diseases' soon followed, while commercially available products were introduced for the treatment of other human diseases.

Many excellent, eloquent and comprehensive reviews covering the discovery, advent, development, manufacture and distribution of ivermectin have been published by those intimately involved with the various stages. ${ }^{1-14}$ It would be folly to replicate those here. Instead, it is the current status, beneficial global health impact and exciting future potential that ivermectin has to offer to human health worldwide that will be the focus of attention.

Today, ivermectin remains a relatively unknown drug, although few, if any, other drugs can rival ivermectin for its beneficial impact on human health and welfare. Ivermectin is a broad-spectrum antiparasitic agent, primarily deployed to combat parasitic worms in veterinary and human medicine. This unprecedented compound has mainly been used in humans as an oral medication for treating filarial diseases but is also effective against other worm-related infections and diseases, plus several parasite-induced epidermal parasitic skin diseases, as well as insect infestations. It is approved for human use in several countries, ostensibly to treat Onchocerciasis, lymphatic filariasis (also known as Elephantiasis), strongyloidiasis and/or scabies and, very recently, to combat head lice. However, health workers are increasingly utilizing it in an unsanctioned manner to treat a diverse range of other diseases, as shown in Appendix 1.

\section{THE PAST: UNMATCHED SUCCESSES}

Perhaps more than any other drug, ivermectin is a drug for the world's poor. For most of this century, some 250 million people have been taking it annually to combat two of the world's most devastating, disfiguring, debilitating and stigma-inducing diseases, Onchocerciasis and Lymphatic filariasis. Most of the recipients live in remote, rural, desperately under-resourced communities in developing countries and have virtually no access to even the most rudimentary of medical interventions. Moreover, all the treatments have been made available free of charge thanks to the unprecedented drug donation program.

When the avermectins were discovered, they represented a completely new class of compounds, 'endectocides', so designated because they killed a diverse range of disease-causing organisms-as well as pathogen vectors-inside as well as outside the body. The first publications on avermectin appeared in 1979, describing it as a complex mixture of 16-membered macrocyclic lactones produced by fermentation of the actinomycete Streptomyces avermitilis-later re-classified as $S$. avermectinius (Figure 2). The avermectin family displayed extraordinarily potent anthelmintic properties. ${ }^{15-17}$ Ivermectin is a safer, more potent semisynthetic mixture of two chemically modified avermectins, comprising $80 \%$ of 22,23-dihydroavermectinB1a and 20\% 22,23-dihydroavermectin-B1b (Figure 3). 
Ivermectin was a revelation. It had a broad spectrum of activity, was highly efficacious, acting robustly at low doses against a wide variety of nematode, insect and acarine parasites. It proved to be extremely effective against most common intestinal worms (except tapeworms), could be administered orally, topically or parentally and showed no signs of cross-resistance with other commonly used anti-parasitic compounds. Marketed in 1981, it quickly became used worldwide to combat filarial and other infections and infestations in livestock and pets.

Registered for human use in 1987, ivermectin was immediately donated as Mectizan tablets to be used solely to control Onchocerciasis, a skin disfiguring and blinding disease caused by infection with the filarial worm Onchocerca volvulus, which afflicted millions of poor families throughout the tropics. Some 20-40 million people were infected prior to the launch of large-scale control interventions, with around 200 million more at risk of infection. ${ }^{18-20}$ Human infection has been tackled in endemic areas through annual or semi-annual mass drug administration of ivermectin and only 21-22 million people (almost exclusively in Africa) remain infected with O. volvulus. ${ }^{21}$

Since the prodigious drug donation operation began, 1.5 billion treatments have been approved. Latest figures show that an estimated

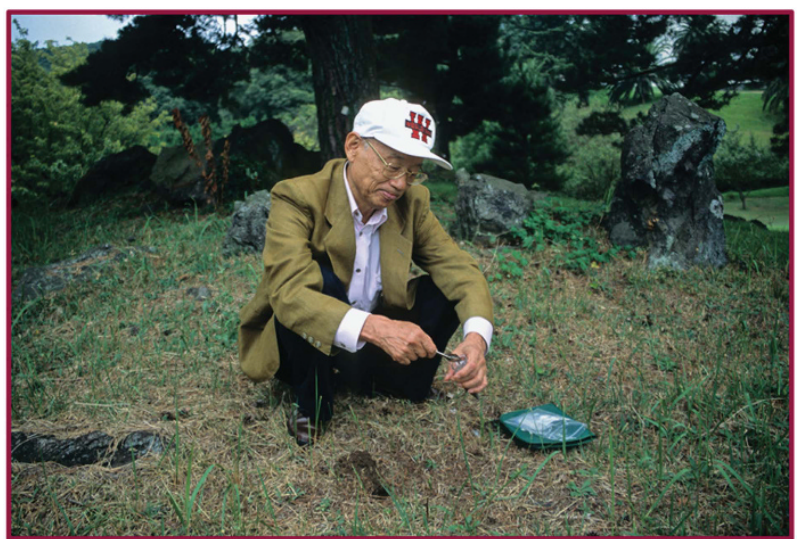

Figure 1 Satoshi Ōmura collecting soil from the very site where the fateful sample containing Streptomyces avermectinius (S. avermitilis) was taken in 1973. (Photo credit: Andy Crump).

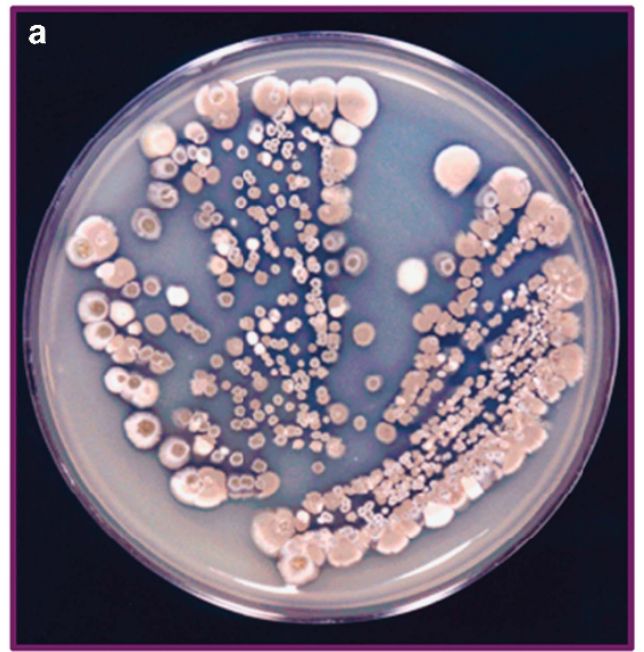

186.6 million people worldwide are still in need of treatment, with over 112.7 million people being treated yearly, predominantly in Africa. ${ }^{22}$ Actual treatments declined in 2014/2015 due to the planned closure of the highly successful and innovative African Programme for Onchocerciasis Control and a subsequent delay before the more comprehensive replacement, the Expanded Special Project for the Elimination of Neglected Tropical Diseases in Africa, became established and operational, plus deferment of some treatments until 2016.

The African Programme for Onchocerciasis Control was created in 1995 to establish community-directed treatment with ivermectin to control Onchocerciasis as a public health problem in African nations that represented $80 \%$ of the global disease burden. For long the sole

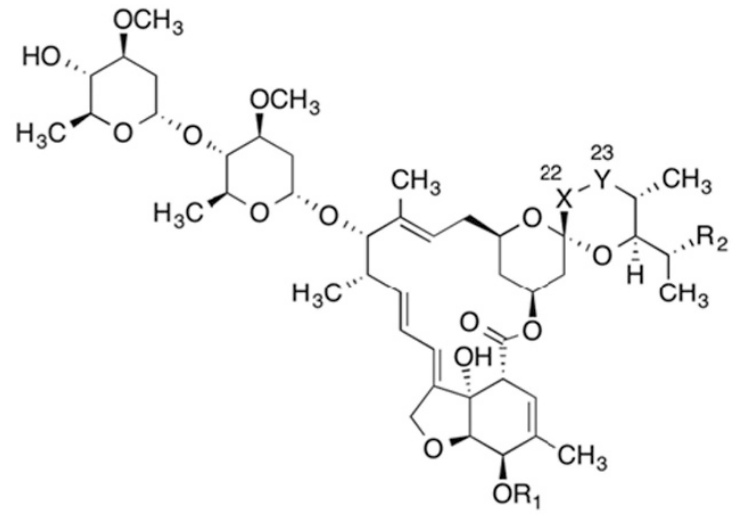

Avermectin $\mathrm{A}_{1 \mathrm{a}}\left[\mathrm{R}_{1}=\mathrm{CH}_{3} ; \mathrm{R}_{2}=\mathrm{C}_{2} \mathrm{H}_{5} ; \mathrm{X}-\mathrm{Y} \Rightarrow 2=\mathrm{s}\right]$

$\mathrm{A}_{1 \mathrm{~b}}\left[\mathrm{R}_{1}=\mathrm{R}_{2}=\mathrm{CH}_{3} ; \mathrm{X}-\mathrm{Y} \Rightarrow \mathrm{Z}_{2}=\mathrm{N}\right]$

$\mathrm{A}_{2 \mathrm{a}}\left[\mathrm{R}_{1}=\mathrm{CH}_{3} ; \mathrm{R}_{2}=\mathrm{C}_{2} \mathrm{H}_{5} ; \mathrm{X}-\mathrm{Y}=\mathrm{CH}_{2}-\mathrm{CH}(\alpha-\mathrm{OH})\right]$

$\mathrm{A}_{2 b}\left[\mathrm{R}_{1}=\mathrm{R}_{2}=\mathrm{CH}_{3} ; \mathrm{X}-\mathrm{Y}=\mathrm{CH}_{2}-\mathrm{CH}(\alpha-\mathrm{OH})\right]$

$\mathrm{B}_{1 \mathrm{a}}\left[\mathrm{R}_{1}=\mathrm{H} ; \mathrm{R}_{2}=\mathrm{C}_{2} \mathrm{H}_{5} ; \mathrm{X}-\mathrm{Y} \Rightarrow z_{2}=\mathrm{s}\right]$

$\mathrm{B}_{1 \mathrm{~b}}\left[\mathrm{R}_{1}=\mathrm{H} ; \mathrm{R}_{2}=\mathrm{CH}_{3} ; \mathrm{X}-\mathrm{Y} \Rightarrow \eta_{2}=\mathrm{s}^{\mathrm{s}}\right]$

$B_{2 a}\left[R_{1}=H ; R_{2}=C_{2} H_{5} ; X-Y=C_{2}-C H(\alpha-O H)\right]$

$B_{2 b}\left[R_{1}=H ; R_{2}=\mathrm{CH}_{3} ; X-Y=\mathrm{CH}_{2}-\mathrm{CH}(\alpha-\mathrm{OH})\right]$

Ivermectin: mixture of dihydroderivatives of

$$
\mathrm{B}_{1 \mathrm{a}}\left[\mathrm{R}_{1}=\mathrm{H} ; \mathrm{R}_{2}=\mathrm{C}_{2} \mathrm{H}_{5} ; \mathrm{X}-\mathrm{Y}=\mathrm{CH}_{2}-\mathrm{CH}_{2}\right]
$$$$
B_{1 b}\left[R_{1}=\mathrm{H} ; R_{2}=\mathrm{CH}_{3} ; X-Y=\mathrm{CH}_{2}-\mathrm{CH}_{2}\right]
$$

Figure 3 The molecular structure of avermectin, a complex of several compounds, which then underwent chemical modification to produce ivermectin, a combination of two dihydroderivatives.

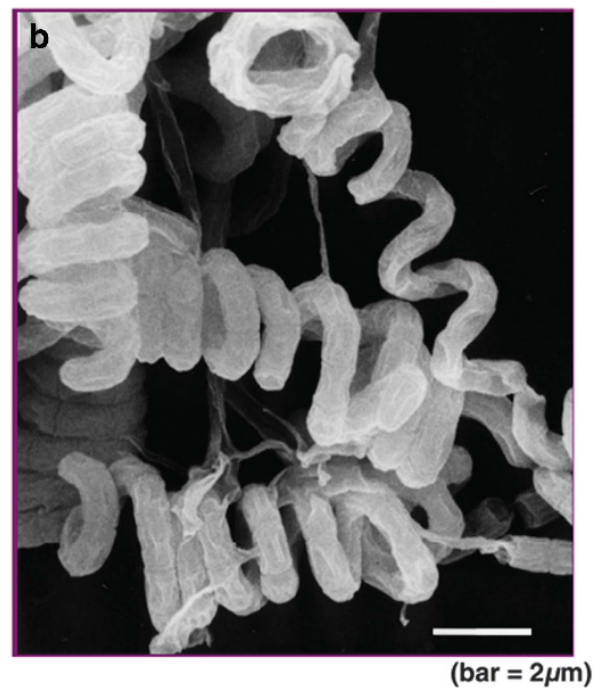

Figure 2 S. avermitilis, sole source of the avermectins: (a) colony and (b) photomicrograph. (Photo credits: Kitasato Institute). 

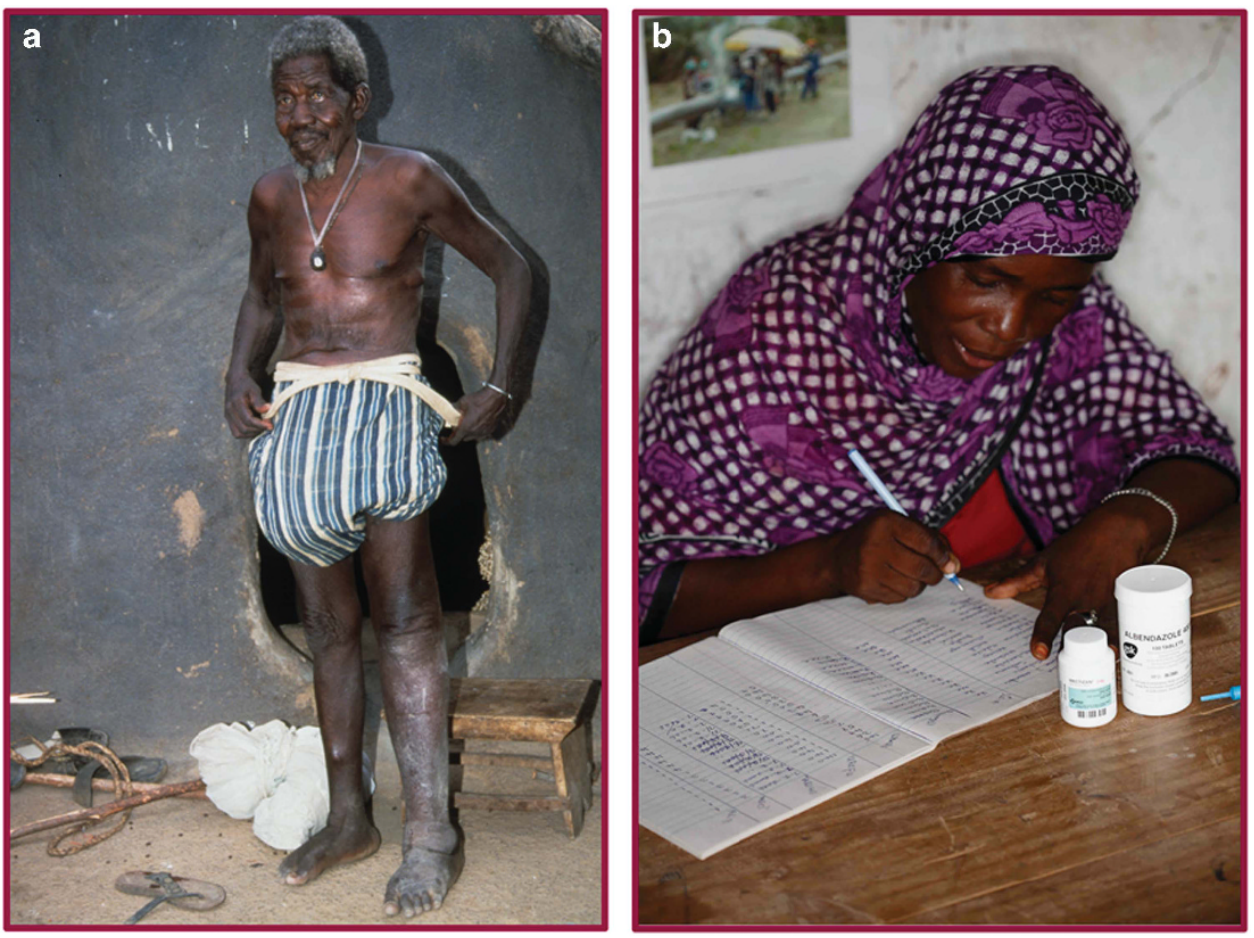

Figure 4 (a) An African man with blindness, skin damage and disfigurement due to Onchocerciasis and Lymphatic filariasis. (b) A community-directed distributor of ivermectin recording the administration of a combination of ivermectin with albendazole, used to treat and protect individuals in areas where the two diseases co-exist—-both diseases being poised for elimination as public health problems within a decade. (Photo credits: Andy Crump).

agent used in control efforts, ivermectin has been so successful that the goal has now switched from disease control to worldwide disease elimination. For most afflicted countries, nationwide Onchocerciasis elimination is within reach and there is hope that the global elimination target of 2025 will be achieved. ${ }^{23}$ Latest models indicate that if the 2025 target (or sooner) is to be achieved, 1.15 billion more treatments will be required, ${ }^{24}$ assuming that the absence of drug resistance continues.

In the mid-1990s, ivermectin was found to be an excellent treatment for Lymphatic filariasis, leading to the donation program being extended to cover this disease in areas where it co-exists with Onchocerciasis (Figure 4). In 2015, almost 374 million people required ivermectin for Lymphatic filariasis, with 176.5 million being treated. ${ }^{25}$ In 2015, 120.7 million ivermectin treatments were approved for Lymphatic filariasis, an accumulated 1.2 billion treatments being authorized since the drug donation program was extended to cover the second disease in $1998 .{ }^{26}$

During 2016, well over 900 million donated ivermectin tablets should be dispatched, representing more than 325 million treatments. ${ }^{22}$

Ivermectin mass drug administration also bestows significant secondary community-wide health and socioeconomic benefits due to its impact on non-target infections. ${ }^{13}$ During 1995-2010, it was estimated that the disability-adjusted life years averted via the impact on these non-target diseases added a further 500000 disabilityadjusted life years to the African Programme for Onchocerciasis Control's 19.1 million saved due to Onchocerciasis interventions. ${ }^{27}$

Surprisingly, despite 40 years of unmatched global success, plus widespread intensive scientific study in both the public and private sectors, scientists are still not certain exactly how ivermectin works. Moreover, whereas ivermectin-resistant parasites swiftly appeared in treated animals, ${ }^{28}$ as well as in ectoparasites, such as copepods parasitizing salmon in fish farms, ${ }^{29}$ somewhat bizarrely and almost uniquely, no confirmed drug resistance appears to have arisen in parasites in human populations, even in those that have been taking ivermectin as a monotherapy for over 30 years.

\section{THE PRESENT: A PUZZLE}

The avermectins potentiate neurotransmission by disrupting glutamate-gated chloride channels, as well as having minor effects on $\gamma$-aminobutyric acid (GABA) receptors. They disrupt neurotransmission in nerve and muscle cells, causing hyperpolarisation of the neuronal membrane, inducing paralysis of somatic muscles, particularly the pharyngeal pump, killing the parasites. GABA-related channels are commonplace throughout nematodes and insects, whereas in mammals, GABA receptors and neurons are restricted to the central nervous system. Ivermectin is therefore very safe for vertebrates, as it cannot cross the blood-brain barrier. Adult filarial worms (macrofilariae), once paired, do not require substantial movement or pharyngeal pumping. Consequently, ivermectin treatment results in a rapid and almost total (98\%) reduction in dermal-dwelling immature worms (microfilariae), ${ }^{30}$ but has only a limited sterilizing effect on female macrofilariae. ${ }^{31}$

Ivermectin's mode of action against parasites in the human body remains to be clarified. There is a substantial disparity between maximum plasma concentrations after ivermectin administration and the concentrations needed to induce paralysis in microfilariae. Support has been accumulating for the evidenced-based hypothesis that the clearance of microfilariae is governed by immunoregulatory processes.

Ivermectin treatment causes microfilariae to quickly disappear from the peripheral skin lymphatics, with long-lasting effect, the high lipid solubility of ivermectin resulting in it being widely distributed throughout the body. Following oral administration, mean peak plasma concentration occurs approximately $4 \mathrm{~h}$ after dosing, a second peak at $6-12 \mathrm{~h}$ probably arising because of enterohepatic recycling of 

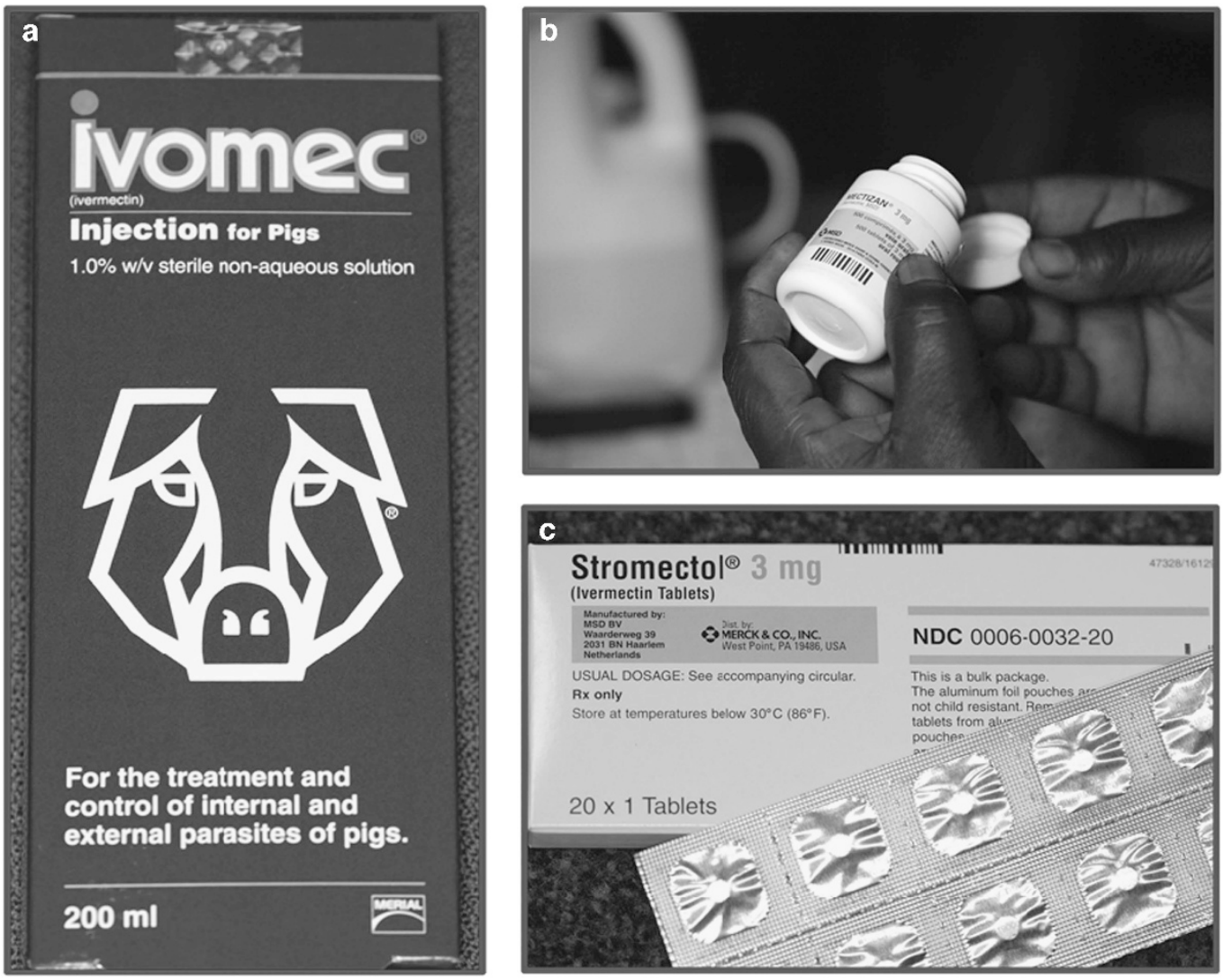

Figure 5 Ivermectin has been formulated in a variety of ways, for example, as an injectable solution for livestock (a); donated as tablets for human use to treat Onchocerciasis (b); and as a commercial tablet preparation for scabies and strongyloidiasis (c). (Photo credits: Andy Crump). A full color version of this figure is available at The Journal of Antibiotics journal online.

the drug, with the plasma half-life of ivermectin being around 12 h. $^{32-34}$ Dermal microfilarial loads are reduced by $78 \%$ within 2 days, and by some $98 \%$ within 2 weeks of treatment, remaining at extremely low levels for about 12 months. As lowest levels of microfilariae occur well after ivermectin administration, they are not necessarily killed when plasma drug levels are highest.

Ivermectin's primary target is glutamate-gated chloride channels, although it also active against other invertebrate neurotransmitter receptors, including GABA-, histamine- and $\mathrm{pH}$-sensitive chloride channels. ${ }^{35-37}$ In addition, ivermectin exposure alters expression of genes involved in the reproduction mechanism of female worms, even at low concentrations. ${ }^{38,39}$

Latterly, research has indicated that glutamate-gated chloride channels activity is solely expressed in musculature surrounding the filarial excretory-secretory vesicle, suggesting that chemicals originating from the excretory-secretory vesicle are regulated by the activity. ${ }^{40}$ It is increasingly believed that the rapid microfilarial clearance following ivermectin dosing results not from the direct impact of the drug but via suppression of the parasite's ability to evade the host's natural immune defense mechanism. ${ }^{41-49}$ Immunomodulatory agents often display fewer side effects than drugs, as well as producing less opportunity for creation of resistance in target microorganisms, which helps explain the absence of drug resistance in humans.

\section{THE FUTURE: NEW POTENTIAL/NEW TARGET DISEASES}

Ivermectin is already deployed to treat a variety of infections and diseases, most of which primarily afflict the world's poor. But it is the new opportunities with respect to ivermectin usage, or re-purposing it to control a completely new range of diseases, that is generating interest and excitement in the scientific and global health research communities.

Ivermectin is registered for human use primarily to treat Onchocerciasis and strongyloidiasis, and, in combination with albendazole, to combat Lymphatic filariasis, as well as being increasingly used 'off-label' to combat a variety of other diseases. Oral treatments are commonplace, but ivermectin doses have also been given successfully per rectum, subcutaneously and topically (Figure 5). Ivermectin has now been used for over three decades to treat parasitic infections in mammals, and has an extremely good safety profile, with numerous studies reporting low rates of adverse events when given as an oral treatment for parasitic infections. ${ }^{50}$ Several problematic reactions have been recorded, but they are generally mild and usually do not necessitate discontinuation of the drug.

In addition to the gradual appreciation of the diverse and invaluable health and socioeconomic benefits that ivermectin use can provide, research is currently shedding light on the promise that the drug still harbors and the prospects of it combatting a new range of diseases or killing vectors of various disease-causing parasites.

The following are an indication of the divergent disease-fighting potential that has been identified for ivermectin thus far:

\section{Myiasis}

Myiasis is an infestation of fly larvae that grow inside the host. Surgical removal of parasites is often the only remedy but unavailable to many of the needful people who live in poor, rural tropical communities where myiatic flies thrive. Oral myiasis has been successfully treated 
with ivermectin, ${ }^{51}$ which has also been used effectively as a noninvasive treatment for orbital myiasis, a rare and preventable ocular morbidity. ${ }^{52}$

\section{Trichinosis}

Globally, approximately 11 million individuals are infected with Trichinella roundworms. Ivermectin kills Trichinella spiralis, the species responsible for most of these infections. ${ }^{53}$

\section{Disease vector control}

Ivermectin is highly effective in killing a broad range of insects. Comprehensive testing against 84 species of insects showed that avermectins were toxic to almost all the insects tested, including the vectors of malaria and critical neglected tropical diseases such as leishmaniasis and trypanosomiasis (see below). At sub-lethal doses, ivermectin inhibits feeding and disrupts mating behavior, oviposition, egg hatching and development. ${ }^{54,55}$

\section{Malaria}

Mosquitoes (Anopheles gambiae) that transmit Plasmodium falciparum, the most dangerous malaria-causing parasite, can be killed by the ivermectin present in the human bloodstream after a standard oral dose. ${ }^{56-59}$ Meanwhile, it has been demonstrated that even at submicromolar levels, ivermectin inhibits the nuclear import of polypeptides of the signal recognition particle of $P$. falciparum (PfSRP), thereby killing the parasites. Consequently, in combination with other anti-malarial agents, ivermectin could become a useful, novel malaria transmission control tool. ${ }^{60,61}$ The use of ivermectin as an additional malaria control weapon is now receiving increased attention, driven by the growing importance of outdoor/residual malaria transmission and the threat of insecticide resistance. One outcome has been the creation of the 'Ivermectin Research for Malaria Elimination Network'. ${ }^{62}$

\section{Leishmaniasis}

Ivermectin has been proposed as a possible rodent-bait feed-through insecticide to help control the Phlebotomine sandfly vectors that transmit Leishmania parasites. ${ }^{63,64}$ Experiments to test the impact of ivermectin on one blood-feeding sandfly vector, Phlebotomus papatasi, demonstrated that they die if the blood feed is 1-2 days post treatment. Although Leishmania major promastigotes have been shown to die or lose their infectivity after exposure to ivermectin, it does not have a major impact against L. major. Nevertheless, ivermectin is more effective in killing promastigotes than rifampicin, nystatin and erythromycin. ${ }^{65,66}$ For cutaneous leishmaniasis, ivermectin is more effective than other drugs (including pentostam, rifampicin, amphotericin B, berenil, metronidazole and nystatin) in killing Leishmania tropica parasites in vitro and by subcutaneous inoculation, with accelerated skin ulcer healing. ${ }^{60}$ When combined with proper surgical wound dressing, ivermectin shows significant promise for curing cutaneous leishmaniasis. ${ }^{67}$

\section{African trypanosomiasis (sleeping sickness)}

Tsetse flies (Glossina palpalis) fed on ivermectin-treated animals die within 5 days, demonstrating that ivermectin has promise to help control these African trypanosomiasis vectors. ${ }^{68,69}$ Effective in killing tsetse flies, experiments in mice infected with Trypanosoma brucei brucei parasites have also shown that ivermectin treatment doubled their survival time, suggesting that there is scope for investigating the use of ivermectin in the treatment of African trypanosomiasis from several aspects. ${ }^{70}$

\section{American trypanosomiasis (Chagas disease)}

When dogs infected with Trypanosoma cruzi parasites suffered a tick infestation, ivermectin treatment eliminated the ticks but had no impact on either the dogs or their infection. Triatomine bug vectors of T. cruzi feeding on the dogs relatively soon after treatment displayed high mortality, which declined rapidly as the interval between ivermectin treatment and blood feed increased. ${ }^{71}$

\section{Schistosomiasis}

Schistosoma species are the causative agent of schistosomiasis, a disease afflicting more than 200 million people worldwide. Praziquantel is the sole drug available for controlling schistosomiasis, with schistosome-resistant parasites now becoming an increasingly worrying problem. ${ }^{72,73}$ Ivermectin is a potent agonist of glutamate-gated chloride channels and as glutamate signaling has been recorded in schistosomes, ${ }^{74,75}$ there may be an ivermectin target in the tegument. Workers in Egypt evaluating the effect of ivermectin on mice infected with Schistosoma mansoni, concluded that ivermectin has promising anti-schistosomal effects. It has potential due to its schistosomicidal activity on adult worms, especially females, and its ovicidal effect, in addition to its impact in improving hepatic lesions. ${ }^{76,77}$ It has also been reported that ivermectin can kill Biomphalaria glabrata, intermediate host snails involved in the schistosomiasis re-infection cycle, reinforcing the prospect of using ivermectin to help control one of the world's major neglected tropical diseases. ${ }^{78,79}$

\section{Bedbugs}

Bedbugs are parasitic insects of the Cimicidae family that feed exclusively on blood. Cimex lectularius, the common bedbug, feeds on human blood, with infestations increasing significantly in poor households across North America and Europe. Ivermectin is highly effective against bedbugs, capable of eradicating or preventing bedbug infestations. ${ }^{80}$

\section{Rosacea}

Although the broad-spectrum anti-parasitic effects of ivermectin are well documented, its anti-inflammatory capacity has only relatively recently been identified. Ivermectin is used 'off-label' to treat diseases associated with Demodex mites, such as blepharitis and demodicosis, oral ivermectin, in combination with topical permethrin, being a safe and effective treatment for severe demodicosis. ${ }^{81}$ Demodex mites have also been linked to rosacea, a chronic skin condition that manifests as recurrent inflammatory lesions. Long-term treatment is required to control symptoms and disease progression, with topical medicaments being the first-line choice. Ivermectin $1 \%$ cream is a new once-daily topical treatment for rosacea lesions, more effective and safer than all current options, ${ }^{82}$ which has recently received approval from American and European authorities for the treatment of adults with rosacea lesions.

\section{Asthma}

A 2011 study investigated the impact of ivermectin on allergic asthma symptoms in mice and found that ivermectin (at $2 \mathrm{mg} \mathrm{kg}^{-1}$ ) significantly curtailed recruitment of immune cells, production of cytokines in the bronchoalveolar lavage fluids and secretion of ovalbumin-specific $\operatorname{IgE}$ and $\operatorname{IgG} 1$ in the serum. Ivermectin also suppressed mucus hypersecretion by goblet cells, establishing that ivermectin can effectively curb inflammation, such that it may be useful in treating allergic asthma and other inflammatory airway diseases. $^{83}$ 


\section{Epilepsy}

Nodding syndrome (NS) is a mysterious and problematic form of epilepsy that occurs in parts of South Sudan and northern Uganda. It is also endemic in a locus in Tanzania but, there, the prevalence is low and stable. ${ }^{84,85}$ The condition has serious socioeconomic implications and, like other forms of epilepsy, generates profound social stigma. ${ }^{86}$ The obvious outward feature of NS, which afflicts children and adolescents, is a paroxysmal bout of forward and downward head movement, the nodding episodes representing epilepsy seizures. ${ }^{87}$ Children with NS display varying levels of mental retardation, often alongside notable stunted growth and failure to develop secondary sexual characteristics (hyposexual dwarfism). Affected children are outwardly healthy until the nodding episodes begin, with several dying due to uncontrolled seizures. ${ }^{84}$ The cause of NS remains unknown but there appears to be an unexplained link with Onchocerciasis infection. ${ }^{88-90}$ The African Programme for Onchocerciasis Control, which operated in the three afflicted countries, adopted mass drug administration of ivermectin in 1997. However, it was not always possible to operate in conflict-affected regions. After the civil war in northern Uganda ceased, biannual ivermectin distribution in districts affected by both Onchocerciasis and NS since 2012 has coincided with a substantial drop in the number of new NS cases. No new cases were reported in 2013, although there is no conclusive evidence to prove any connection. ${ }^{91}$

\section{Neurological disease}

Many neurological disorders, such as motor neurone disease, arise due to cell death initiated by excessive levels of excitation in central nervous system neurons. A proposed novel therapy for these disorders involves silencing excessive neuronal activity using ivermectin. Because of its action on $\mathrm{P} 2 \mathrm{X} 4$ receptors, ivermectin has potential with respect to preventing alcohol use disorders ${ }^{92}$ as well as for motor neurone disease. $^{93}$ Indeed, in 2007, Belgian scientists applied for a patent, 'Use of ivermectin and derivates thereof for the treatment of amyotrophic lateral sclerosis' (Publication No.: WO/2008/034202A3), to cover 'the use of ivermectin and analogs, to prevent, retard and ameliorate a motor neuron disease such as amyotrophic lateral sclerosis and the associated motor neuron degeneration'.

Recent work has elucidated how ivermectin binds to target receptors and helped explain its selectivity for invertebrate Cys-loop receptors. Combined with emerging genomic information, species sensitivity to ivermectin can now be predicted and the molecular basis of ivermectin resistance has become clearer. In humans, Cys-loop neurotransmitter receptors, particularly those activated by GABA, mediate rapid synaptic transmission throughout the nervous system and are crucial for intercellular communication. They are key factors in fundamental physiological processes, such as learning and memory, and in several neurological disorders, making them attractive drug targets. ${ }^{94}$ Improved understanding of the stereochemistry of ivermectin binding will facilitate the development of new lead compounds, as anthelmintics as well as treatments for a wide variety of human neurological disorders. ${ }^{95,96}$

\section{Antiviral (e.g. HIV, dengue, encephalitis)}

Recent research has confounded the belief, held for most of the past 40 years, that ivermectin was devoid of any antiviral characteristics. Ivermectin has been found to potently inhibit replication of the yellow fever virus, with $\mathrm{EC}_{50}$ values in the sub-nanomolar range. It also inhibits replication in several other flaviviruses, including dengue, Japanese encephalitis and tick-borne encephalitis, probably by targeting non-structural 3 helicase activity. ${ }^{97}$ Ivermectin inhibits dengue viruses and interrupts virus replication, bestowing protection against infection with all distinct virus serotypes, and has unexplored potential as a dengue antiviral. ${ }^{98}$

Ivermectin has also been demonstrated to be a potent broadspectrum specific inhibitor of importin $\alpha / \beta$-mediated nuclear transport and demonstrates antiviral activity against several RNA viruses by blocking the nuclear trafficking of viral proteins. It has been shown to have potent antiviral action against HIV-1 and dengue viruses, both of which are dependent on the importin protein superfamily for several key cellular processes. Ivermectin may be of import in disrupting HIV-1 integrase in HIV-1 as well as NS-5 (non-structural protein 5) polymerase in dengue viruses. ${ }^{99,100}$

\section{Antibacterial (tuberculosis and Buruli ulcer)}

Up until recently, avermectins were also believed to lack antibacterial activity. However, in 2012, reports emerged that ivermectin was capable of preventing infection of epithelial cells by the bacterial pathogen Chlamydia trachomatis, and to do so at doses that could be used to counter sexually transmitted or ocular infections. ${ }^{101}$ In 2013, researchers confirmed that ivermectin was bactericidal against a range of mycobacterial organisms, including multidrug resistant and extensively drug-resistant strains of Mycobacterium tuberculosis, the authors suggesting that ivermectin could be re-purposed for tuberculosis treatment. Although other researchers found that ivermectin does not possess anti-tuberculosis activity, the results were later shown to be non-comparable due to differences in testing methods, with the original findings being confirmed by further work in Japan. ${ }^{102-104}$ Unfortunately, the potential use of ivermectin for tuberculosis treatment is doubtful due to possible neurotoxicity at high dosage levels. Ivermectin was also reported to be bactericidal against $M$. ulcerans, ${ }^{105}$ although other researchers found no significant activity against this bacterium. ${ }^{106}$

\section{Anti-cancer}

There is a continuously accumulating body of evidence that ivermectin may have substantial value in the treatment of a variety of cancers. The avermectins are known to possess pronounced antitumor activity, ${ }^{107}$ as well as the ability to potentiate the antitumor action of vincristine on Ehrlich carcinoma, melanoma B16 and P388 lymphoid leukemia, including the vincristine-resistant strain P388. ${ }^{108}$

Over the past few years, there have been steadily increasing reports that ivermectin may have varying uses as an anti-cancer agent, as it has been shown to exhibit both anti-cancer and anti-cancer stem cell properties. An in silico chemical genomics approach designed to predict whether any existing drugs might be useful in tackling glioblastoma, lung and breast cancer, indicated that ivermectin may be a useful compound in this respect. ${ }^{109}$

In human ovarian cancer and NF2 tumor cell lines, high-dose ivermectin inactivates protein kinase PAK1 and blocks PAK1dependent growth. PAK proteins are essential for cytoskeletal reorganization and nuclear signaling, PAK1 being implicated in tumor genesis while inhibiting PAK1 signals induces tumor cell apoptosis (cell death).

PAK1 is essential for the growth of more than $70 \%$ of all human cancers, including breast, prostate, pancreatic, colon, gastric, lung, cervical and thyroid cancers, as well as hepatoma, glioma, melanoma, multiple myeloma and for neurofibromatosis tumors. ${ }^{110}$

Globally, breast cancer is the most common cancer among women but treatment options are few. Ivermectin suppresses breast cancer by activating cytostatic autophagy, disrupting cellular signaling in the process, probably by reducing PAK1 expression. Ivermectin-induced 
cytostatic autophagy also leads to suppression of tumor growth in breast cancer xenografts, causing researchers to believe there is scope for using ivermectin to inhibit breast cancer cell proliferation and that the drug is a potential treatment for breast cancer. ${ }^{111}$ Triple-negative breast cancers, which lack estrogen, progesterone and HER2 receptors, account for $10-20 \%$ of breast cancers and are associated with poor prognosis. Tests using a peptide corresponding to the SIN3 interaction domain (SID) of MAD, found that the SID peptide selectively blocks binding of SID-containing proteins to the paired $\alpha$-helix domain of SIN3, resulting in epigenetic and transcriptional modulation of genes associated with epithelial-mesenchymal transition. An in silico screen identified ivermectin as a promising candidate as a paired $\alpha$-helix domain-binding small molecular weight compound to inhibit SID peptide, ivermectin phenocopying the effects of SID peptide to block SIN3-paired $\alpha$-helix interaction with MAD, inducing expression of $\mathrm{CDH} 1$ and ESR1, and restoring tamoxifen sensitivity in mass drug administration-MB-231 human and MMTV-Myc mouse triple-negative breast cancers cells in vitro. Ivermectin addition led to transcriptional modulation of genes associated with epithelial-mesenchymal transition and maintenance of a cancer stem cell phenotype in triple-negative breast cancers cells, resulting in impairment of clonogenic self-renewal in vitro and inhibition of tumor growth and metastasis in vivo. ${ }^{112}$

It has been reported that ivermectin induces chloride-dependent membrane hyperpolarization and cell death in leukemia cells and it has also been suggested that ivermectin synergizes with the chemotherapy agents cytarabine and daunorubicin to induce cell death in leukemia cells, with researchers claiming that ivermectin could be rapidly advanced into clinical trials. ${ }^{113}$ This potential has been supported by reports that ivermectin displays bioactivity against chronic lymphocytic leukemia cells and against ME-180 cervical cancer cells. ${ }^{114}$ Additionally, ivermectin has been shown to potentiate doxorubicin-induced apoptosis of drug-resistant leukemia cells in mice. ${ }^{115}$ Cancer stem cells are a key factor in cancer cells developing resistance to chemotherapies and these results indicate that a combination of chemotherapy agents plus ivermectin could potentially target and kill cancer stem cells, a paramount goal in overcoming cancer.

Ivermectin inhibits proliferation and increases apoptosis of various human cancers. Over-expression of P2X7 receptors correlates with tumor growth and metastasis. However, ATP release is linked to immunogenic cancer cell death, in addition to inflammatory responses caused by necrotic cell death. Exploiting ivermectin as a prototype agent to allosterically modulate $\mathrm{P} 2 \mathrm{X} 4$ receptors, it should be possible to disrupt the balance between the pro-survival and cytotoxic functions of purinergic signaling in cancer cells. Ivermectin induces autophagy and release of ATP and HMGB1, key mediators of inflammation. Potentiated P2X4/P2X7 signaling can be further linked to ATP-rich tumor environments, providing an explanation of the tumor selectivity of purinergic receptor modulation, confirming ivermectin's potential to be used for cancer immunotherapy. ${ }^{116}$ Activation of WNT-TCF signaling is implicated in multiple diseases, including cancers of the lungs and intestine, but no WNT-TCF antagonists are in clinical use. A new screening system has found that ivermectin inhibits the expression of WNT-TCF targets. It represses the levels of C-terminal $\beta$-catenin phosphoforms and of cyclin D1 in an okadaic acid-sensitive manner, indicating its action involves protein phosphatases. In vivo, ivermectin selectively inhibits TCF-dependent, but not TCF-independent, xenograft growth without side effects. Because ivermectin has an exemplary safety record, it could swiftly become a useful tool as a WNT-TCF pathway response blocker to treat WNT-TCF-dependent diseases, encompassing multiple cancers. ${ }^{117}$

Researchers have recently reported a direct interaction between ivermectin and nematode and human tubulin, even at micromolar concentrations. When added to human $\mathrm{HeLa}$ cells, ivermectin stabilizes tubulin against depolymerizing effects and prevents replication of the cells in vitro, although the inhibition is reversible. This suggests that ivermectin binds to and stabilizes mammalian microtubules. Ivermectin thus affects tubulin polymerization and depolymerization dynamics, which can cause cell death. Again, given that ivermectin is already approved for use in humans, its rapid development as an anti-mitotic agent offers significant promise. ${ }^{118}$

\section{NOVEL DELIVERY SYSTEMS}

Drug delivery mechanisms can affect drug pharmacokinetics, absorption, distribution, metabolism, duration of therapeutic effect, excretion and toxicity. As new therapeutics appear, there is an accompanying necessity for improved chemistries and novel materials and mechanisms to target their delivery (including to currently impractical/inaccessible locations), at efficacious therapeutic concentration, and for the required period of time. ${ }^{119}$ Ivermectin is one of the most extensively used anti-parasitic agents worldwide. However, as with most drugs, minor variations in formulation may change the plasma kinetics, the biodistribution, and consequentially, its efficacy. It has already been demonstrated that oral solutions produce twice the systemic availability than solid forms (tablets or capsules). ${ }^{34}$ As shown in Appendix 2, the possibility of novel systems for delivering ivermectin opens up a plethora of opportunities for usage of the drug against currently targeted diseases, as well as realizing its potential to combat a totally new range of diseases and conditions. It may therefore be likely that novel formulations and delivery systems, such as those in Appendix 2, as well as ivermectin-containing skin patches, slow-release formulations, oral solutions, ivermectin-impregnated clothing or newly discovered time-sensitive shape-shifting materials, may become innovative and effective means of delivering the drug in the near future. They may well also create innovative, cost-effective delivery mechanisms to revitalize existing uses of ivermectin.

As a further indication of the increasing attention being paid to ivermectin, in 2013, Chinese scientists applied for an international patent 'Use of ivermectin and derivatives thereof' (Publication No.: $\mathrm{WO} / 2014 / 059797$ ) for new uses in the 'development and manufacture of medicaments for human use in treating metabolic related diseases, such as hyperglycemia, insulin resistance, hypertriglyceridemia, hypercholesterolemia, diabetes, obesity and so on, and Famesoid X receptor-mediated diseases, such as cholestasia, gallstones, non-alcohol fatty liver disease, atherosclerosis, inflammation and cancer'.

Essentially, a unique, multifaceted 'wonder' drug of the past and present may yet become an even more exceptional drug of the future.

\section{CONFLICT OF INTEREST}

The author declares no conflict of interest.

\section{ACKNOWLEDGEMENTS}

Having spent a good deal of time during the past 25 years among remote rural communities in Africa while following the ivermectin story, I wish to convey to Satoshi Ōmura the grateful thanks of millions of men, women and children in such communities whose health, nutrition, education, economic situation and social status have been immeasurably improved by their access to ivermectin. Without his innovation, vision, drive and unwavering commitment, their lives and livelihoods would still be blighted by disease and misery. I also wish to convey my profound thanks to him for the opportunity of working 
alongside him and for his personal friendship, chivalry and tutelage in the art of interpersonal respect and understanding in the pursuit of all partnerships and collaborative endeavors.

1 Campbell, W. C., Fisher, M. H., Stapley, E. O., Albers-Schönberg, G. \& Jacob, T. A. Ivermectin: a potent antiparasitic agent. Science 221, 823-828 (1983).

2 Campbell, W. C. Ivermectin: an update. Parasitol. Today 1, 10-16 (1985).

3 Campbell, W. C. Ivermectin and Abamectin 325 (Springer-Verlag, New York, 1989).

4 Campbell, W. C. Use of Ivermectin in Humans 311-323 (Springer-Verlag, New York, 1989).

5 Campbell, W. C. Ivermectin as an antiparasitic agent for use in humans. Ann. Rev. Microbiol. 45, 445-474 (1991).

6 Campbell, W. C. in Inventive Mindseds (eds Weber R. J. \& Perkins D. N.) 194-214 (Oxford University Press, New York, 1992).

7 Ōmura, S. \& Crump, A. The life and times of ivermectin-a success story. Nat. Rev. Microbiol. 2, 984-989 (2004).

8 Geary, T. G. Ivermectin 20 years on: maturation of a wonder drug. Trends Parasitol. 21, 530-532 (2005).

9 Ōmura, S. Ivermectin: 25 years and still going strong. Int. J. Antimicrob. Agents $\mathbf{3 1}$, 91-98 (2008).

10 Campbell, W. C. History of avermectin and ivermectin, with notes on the history of other macrocyclic lactone antiparasitic agents. Curr. Pharm. Biotechnol. 13, 853-865 (2012).

11 Crump, A. \& Ōmura, S. Ivermectin, 'wonder drug' from Japan: the human use perspective. Proc. Jpn Acad. Ser. B Phys. Biol. Sci. 87, 13-28 (2011).

12 Crump, A., Morel, C. M. \& Ōmura, S. The onchocerciasis chronicle: from the beginning to the end? Trends Parasitol. 28, 280-288 (2012).

13 Ōmura, S. \& Crump, A. Ivermectin: panacea for resource-poor communities? Trends Parasitol. 30, 445-455 (2014).

14 Ōmura, S. Nobel lecture: a splendid gift from the Earth: the origins and impact of the avermectins. Angew. Chem. Int. Ed. Engl. 55, 10190-10209 (2016).

15 Burg, R. W. et al. Avermectins, new family of potent anthelmintic agents: producing organisms and fermentation. Antimicrob. Agents Chemother. 15, 361-367 (1979).

16 Miller, T. W. et al. Avermectins, new family of potent anthelmintic agents: isolation and chromatographic properties. Antimicrob. Agents Chemother. 15, 368-371 (1979).

17 Egerton, J. R. et al. Avermectins, new family of potent anthelmintic agents: efficacy of the B1A component. Antimicrob. Agents Chemother. 15, 372-378 (1979).

18 World Health Organization. Onchocerciasis and its control report of a WHO Expert Committee on Onchocerciasis Control (WHO/TRS/852) 104, http://apps.who.int/iris/ bitstream/10665/37346/1/WHO_TRS_852.pdf (World Health Organization, Geneva, 1995).

19 Zoure, H. G. et al. The geographic distribution of onchocerciasis in the 20 participating countries of the African Programme for Onchocerciasis Control: (2) pre-control endemicity levels and estimated number infected. Parasit. Vectors 7, 325 (2014).

20 Remme, J. H. F. The African Programme for Onchocerciasis Control: preparing to launch. Trends Parasitol. 11, 403-406 (1995)

21 Coffeng, L. E. et al. African Programme for Onchocerciasis Control 1995-2015: updated health impact estimates based on new disability weights. PLoS Negl. Trop. Dis. 8, e2759 (2014).

22 World Health Organization. Progress report on the elimination of human onchocerciasis, 2015-2016. Wkly Epidemiol. Rec. 91, 505-514 (2016).

23 Tekle, A. H. et al. Progress towards onchocerciasis elimination in the participating countries of the African Programme for Onchocerciasis Control: epidemiological evaluation results. Infect. Dis. Poverty 5, 66 (2016).

$24 \mathrm{Kim}, \mathrm{Y}$. E. et al. Control, elimination and eradication of river blindness: scenarios, timelines, and ivermectin treatment needs in Africa. PLoS Negl. Trop. Dis. 9, e0003664 (2015)

25 World Health Organization. Global programme to eliminate lymphatic filariasis: progress report 2015. Wkly Epidemiol. Rec. 91, 441-455 (2016).

26 Mectizan Donation Program. Annual Highlights: 20158 (Mectizan Donation Programme, Atlanta, Georgia, 2016).

27 Krotneva, S. P. et al. African Program for Onchocerciasis Control 1995-2010: impact of annual ivermectin mass treatment on Off-Target infectious diseases. PLoS Neg/. Trop. Dis. 9, e0004051 (2015).

28 van Wyk, J. A. \& Malan, F. S. Resistance of field strains of Haemonchus contortus to ivermectin, closantel, rafoxanide and the benzimidazoles in South Africa. Vet. Record 123, 226-228 (1988).

29 Horsberg, T. E. Avermectin use in aquaculture. Curr. Pharm. Biotechnol. 13, 1095-1102 (2012).

30 Basanez, M. G. et al. Effect of single-dose ivermectin on Onchocerca volvulus: a systematic review and meta-analysis. Lancet Infect. Dis. 8, 310-322 (2008).

31 Taylor, M. J., Hoerauf, A. \& Bockarie, M. Lymphatic filariasis and onchocerciasis. Lancet 376, 1175-1185 (2010).

32 Fink, D. W. \& Porras, A. G. in Ivermectin and Abamectin (ed. Campbell W. C.) 113-130 (Springer-Verlag, New York, 1989).

33 Baraka, O. Z. et al. Ivermectin distribution in the plasma and tissues of patients infected with Onchocerca volvulus. Eur. J. Clin. Pharmacol. 50, 407-410 (1996).
34 González Canga, A. et al. The pharmacokinetics and interactions of ivermectin in humans-a mini-review. AAPS J. 10, 42-46 (2008).

35 Brown, D. D. R., Siddiqui, S. Z., Kaji, M. D. \& Forrester, S. G. Pharmacological characterization of the Haemonchus contortus GABA-gated chloride channel, Hco-UNC-49: modulation by macrocyclic lactone anthelmintics and a receptor for piperazine. Vet. Parasitol. 185, 201-209 (2012).

36 Zheng, Y. et al. Identification of two novel Drosophila melanogaster histamine-gated chloride channel subunits expressed in the eye. J. Biol. Chem. 277, 2000-2005 (2002).

37 Schnizler, K. et al. A novel chloride channel in Drosophila melanogaster is inhibited by protons. J. Biol. Chem. 280, 16254-16262 (2005).

38 Li, B. W., Rush, A. C. \& Weil, G. J. High level expression of a glutamate-gated chloride channel gene in reproductive tissues of Brugia malayi may explain the sterilizing effect of ivermectin on filarial worms. Int. J. Parasitol. Drugs Drug Resist. 4, 71-76 (2014).

39 Ballesteros, C. et al. The effects of ivermectin on Brugia malayi females in vitro: a transcriptomic approach. PLoS Negl. Trop. Dis. 10, e0004929 (2016).

40 Moreno, Y., Nabhan, J. F., Solomon, J., Mackenzie, C. D. \& Geary, T. G. Ivermectin disrupts the function of the excretory-secretory apparatus in microfilariae of Brugia malayi. Proc. Natl Acad. Sci. USA 107, 20120-20125 (2010).

41 Wolstenholme, A. J., Maclean, M. J., Coates, R., McCoy, C. J. \& Reaves, B. J. How do the macrocyclic lactones kill filarial nematode larvae? Invert. Neurosci. 16, 7 (2016).

42 Kwarteng, A., Terkoper Ahuno, S. \& Osei Akoto, F. Killing filarial nematode parasites: role of treatment options and host immune response. Infect. Dis. Pov. 5, 86 (2016).

43 Higazi, T. B., Geary, T. G. \& Mackenzie, C. D. Chemotherapy in the treatment, control, and elimination of human onchocerciasis. Res. Rep. Trop. Med. 5, 77-93 (2014).

44 Hewitson, J. P., Grainger, J. R. \& Maizels, R. M. helminth immunoregulation: the role of parasite secreted proteins in modulating host immunity. Mol. Biochem. Parasitol. 167, 1-11 (2009).

45 Maizels, R. M., Hewitson, J. P. \& Smith, K. A. Susceptibility and immunity to helminth parasites. Curr. Opin. Immunol. 24, 459-466 (2012).

46 MacDonald, A. J. et al. Differential cytokine and antibody responses to adult and larval stages of Onchocerca volvulus consistent with the development of concomitant immunity. Infect. Immun. 70, 2796-2804 (2002).

47 Ali, M. M. et al. Immunocompetence may be important in the effectiveness of Mectizan (ivermectin) in the treatment of human onchocerciasis. Acta Trop. 84, 49-53 (2002)

48 Brattig, N. W. Pathogenesis and host responses in human onchocerciasis: impact of Onchocerca filariae and Wolbachia endobacteria. Microbes Infect. 6, 113-128 (2004).

49 Dzik, J. M. Molecules released by helminth parasites involved in host colonization. Acta Biochim. Pol. 53, 33-64 (2006).

50 Kircik, L. H., Del Rosso, J. Q., Layton, A. M. \& Schauber, J. Over 25 years of clinical experience with ivermectin: an overview of safety for an increasing number of indications. J. Drugs Dermatol. 15, 325-332 (2016).

51 Shinohara, E. H., Martini, M. Z., de Oliveira Neto, H. G. \& Takahashi, A. Oral myiasis treated with ivermectin: case report. Braz. Dent. J. 15, 79-81 (2004).

52 Pandey, T. R., Shrestha, G. B., Kharel (Sitaula), R. \& Shah, D. N. A case of orbital myiasis in recurrent eyelid basal cell carcinoma invasive into the orbit. Case Rep. Ophthalmol. Med. 2904346, 4 http://dx.doi.org/10.1155/2016/2904346 (2016).

53 Basyoni, M. M. \& El-Sabaa, A. A. Therapeutic potential of myrrh and ivermectin against experimental Trichinella spiralis infection in mice. Korean J. Parasitol. 51, 297-304 (2013).

54 Strong, L. \& Brown, T. A. Avermectins in insect control and biology: a review. Bull. Entomol. Res. 77, 357-389 (1987).

55 Jackson, H. C. Ivermectin as a systemic insecticide. Parasitol. Today 5, 146-156 (1989).

56 Tesh, R. B. \& Guzman, H. Mortality and infertility in adult mosquitoes after the ingestion of blood containing ivermectin. Am. J. Trop. Med. Hyg. 43, 229-233 (1990).

57 Chaccour, C., Lines, J. \& Whitty, C. J. M. Effect of ivermectin on Anopheles gambiae mosquitoes fed on humans; the potential of oral insecticides in malaria control. J. Infect. Dis. 202, 113-116 (2010).

58 Kobylinski, K. C. et al. The effect of oral anthelmintics on the survivorship and re-feeding frequency of anthropophilic mosquito disease vectors. Acta Trop. 116, 119-126 (2010).

59 Kobylinski, K. C., Sylla, M., Chapman, P. L., Sarr, M. D. \& Foy, B. D. Ivermectin mass drug administration for humans disrupts malaria parasite transmission in Senegalese villages. Am. J. Trop. Med. Hyg. 85, 3-5 (2011).

60 Panchal, M. et al. Plasmodium falciparum signal recognition particle components and anti-parasitic effect of ivermectin in blocking nucleo-cytoplasmic shuttling of SRP. Cell Death Dis. 16, e994 (2014).

61 Foy, B. D., Kobylinski, K. C., da Silva, I. M., Rasgon, J. L. \& Sylla, M. Endectocides for malaria control. Trends Parasitol. 27, 423-428 (2011).

62 Chaccour, C. J. et al. Establishment of the ivermectin research for malaria elimination network: updating the research agenda. Malar. J. 14, 243 (2015).

63 Mascari, T. M., Mitchell, M. A., Rowton, E. D. \& Foil, L. D. Ivermectin as a rodent feed-through insecticide for control of immature sand flies (Diptera: Psychodidae). J. Am. Mosq. Control Assoc. 24, 323-326 (2008).

64 Kadir, M. A., Aswad, H. S., Al-Samarai, A. M. \& Al-Mula, G. A. Comparison between the efficacy of ivermectin and other drugs in treatment of cutaneous leishmaniasis. Iraqi J. Vet. Sci. 23(Suppl II), 175-180 (2009). 
65 Hanafi, H. A. et al. Effects of ivermectin on blood-feeding Phlebotomus papatasi and the promastigote stage of Leishmania major. Vector Borne Zoonotic Dis. 11, 43-52 (2011).

66 Rasheid, K. A. \& Morsy, T. A. Efficacy of ivermectin on the infectivity of Leishmania major promastigotes. J. Egypt Soc. Parasitol. 28, 207-212 (1998).

67 Opara, W. E. K. \& Ameh, I. G. Cutaneous leishmaniasis: a report of its treatment with Mectizan in Sokoto, Nigeria. J. Med. Sci. 5, 186-188 (2005).

68 Distelmans, W., D'Haeseleer, F. \& Mortelmans, J. Efficacy of systemic administration of ivermectin against tsetse flies. Ann. Soc. Belg. Med. Trop. 83, 119-125 (1983).

69 Pooda, S. H., Mouline, K., De Meeûs, T., Bengaly, Z. \& Solano, P. Decrease in survival and fecundity of Glossina palpalis gambiensis vanderplank 1949 (Diptera; Glossinidae) fed on cattle treated with single doses of ivermectin. Parasit. Vectors 6 , 165 (2013).

70 Udensi, U. K. \& Fagbenro-Beyioku, A. F. Effect of ivermectin on Trypanosoma brucei brucei in experimentally infected mice. J. Vector Borne Dis. 49, 143-150 (2012).

71 Pinto Dias, J. C. et al. Ticks, ivermectin and experimental Chagas disease. Mem. Inst. Oswaldo Cruz 100, 829-832 (2005).

72 Fallon, P. G. \& Doenhoff, M. J. Drug-resistant schistosomiasis: resistance to praziquantel and oxamniquine induced in Schistosoma mansoni in mice is drug specific. Am. J. Trop. Med. Hyg. 51, 83-88 (1994).

73 Ismail, M. et al. Resistance to praziquantel: direct evidence from Schistosoma mansoni isolated from Egyptian villagers. Am. J. Trop. Med. Hyg. 60, 932-935 (1999).

74 Mendonça-Silva, D. L., Pessôa, R. F. \& Noël, F. Evidence for the presence of glutamatergic receptors in adult Schistosoma mansoni. Biochem. Pharmacol. 64, 1337-1344 (2002)

75 Lynagh, T. \& Lynch, J. W. Ivermectin binding sites in human and invertebrate Cys-loop receptors. Trends Pharmacol. Sci. 33, 432-441 (2012).

76 Taman, A. \& Ribeiro, P. Characterization of a truncated metabotropic glutamate receptor in a primitive metazoan, the parasitic flatworm Schistosoma mansoni. PLoS ONE 6, e27119 (2011).

77 Taman, A., El-Beshbishi, S., El-Tantawy, N., El-Hawary, A. \& Azab, M. Evaluation of the in vivo effect of ivermectin on Schistosoma mansoni in experimentallyinfected mice. J. Coastal Life Med. 2, 817-823 (2014).

78 Nunes Alves, S. \& de Melo, A. L. Effects of benzodiazepine and ivermectin on Girardia tigrina (Platyhelminthes: Turbellaria). Biosci. J. Uberlândia 29, 209-215 (2013).

79 Matha, V. \& Weiser, J. Molluscicidal effect of ivermectin on Biomphalaria glabrata. J. Invertebr. Pathol. 52, 354-355 (1988).

80 Sheele, J. M. et al. Ivermectin causes Cimex lectularius (Bedbug) morbidity and mortality. J. Emerg. Med. 45, 433-440 (2013).

81 Gonser, L., Gonser, C. E. \& Schaller, M. Pathogenesis, clinical picture, and current therapy of rosacea. [In German]. Hautarzt 67, 69-82 (2016).

82 Siddiqui, K., Stein Gold, L. \& Gill, J. The efficacy, safety, and tolerability of ivermectin compared with current topical treatments for the inflammatory lesions of rosacea: a network meta-analysis. Springerplus 5, 1151 (2016).

83 Yan, S. et al. Anti-inflammatory effects of ivermectin in a mouse model of allergic asthma. Inflamm. Res. 60, 589-596 (2011).

84 Dowell, S. F. et al. Nodding syndrome. Emerg. Infect. Dis. 19, 1374-1383 (2013).

85 Winkler, A. S. et al. MRI findings in people with epilepsy and nodding syndrome in an area endemic for onchocerciasis: an observational study. Afr. Health Sci. 13, 529-540 (2013)

86 van Bemmel, K., Derluyn, I. \& Stroeken, K. Nodding syndrome or disease? On the conceptualization of an illness-in-the-making. Ethn. Health 19, 100-118 (2014).

87 Sejvar, J. J. et al. Clinical, neurological, and electrophysiological features of nodding syndrome in Kitgum, Uganda: an observational case seriesLancet Neurol. 12, 166-174 (2013).

88 Kaiser, C., Pion, S. \& Boussinesq, M. Head nodding syndrome and river blindness: a parasitologic perspective. Epilepsia 50, 2325-2326 (2009).

89 Vogel, G. Mystery disease haunts region. Science 336, 144-146 (2012).

90 Foltz, J. L. et al. An epidemiologic investigation of potential risk factors for nodding syndrome in Kitgum District, Uganda. PLOS ONE 8, e66419 (2013).

91 Colebunders, R. et al. Nodding syndrome since 2012: recent progress, challenges and recommendations for future research. Trop. Med. Int. Health 20, 194-200 (2015)

92 Franklin, K. M. et al. P2X4 receptors (P2X4Rs) represent a novel target for the development of drugs to prevent and/or treat alcohol use disorders. Front. Neurosci. 24, 176 (2014).

93 Andries, M., Van Damme, P., Robberecht, W. \& Van Den Bosch, L. Ivermectin inhibits AMPA receptor-mediated excitotoxicity in cultured motor neurons and extends the life span of a transgenic mouse model of amyotrophic lateral sclerosis. Neurobiol. Dis. 25, 8-16 (2007).

94 Bouzat, C. New insights into the structural bases of activation of Cys-loop receptors. J. Physiol. Paris 106, 23-33 (2012).

95 Lynagh, T. \& Lynch, J. W. Ivermectin binding sites in human and invertebrate Cys-loop receptors. Trends Pharmacol. Sci. 33, 432-441 (2012).

96 Estrada-Mondragon, A. \& Lynch, J. W. Functional characterization of ivermectin binding sites in $\alpha 1 \beta 2 \gamma 2 \mathrm{~L}$ GABA(A) receptors. Front. Mol. Neurosci. 8, 55 (2015).

97 Mastrangelo, E. et al. Ivermectin is a potent inhibitor of flavivirus replication specifically targeting NS3 helicase activity: new prospects for an old drug J. Antimcrob. Chemother. 67, 1884-1894 (2012).

98 Tay, M. Y. et al. Nuclear localization of dengue virus (DENV) 1-4 nonstructural protein 5: protection against all 4 DENV serotypes by the inhibitor ivermectin. Antiviral Res. 99, 301-306 (2013)
99 Wagstaff, K. M., Sivakumaran, H., Heaton, S. M., Harrich, D. \& Jans, D. A. Ivermectin is a specific inhibitor of importin $\alpha / \beta$-mediated nuclear import able to inhibit replication of HIV-1 and dengue viruses. Biochem. J. 443(Pt 3), 851-856 (2012).

100 Kosyna, F. K., Nage, M., Kluxen, L., Kraushaar, K. \& Depping, R. The importin $\alpha / \beta$-specific inhibitor ivermectin affects HIF-dependent hypoxia response pathways. Biol. Chem. 396, 1357-1367 (2015).

101 Pettengil, M. A., Lam, V. W., Ollawa, I., Marques-da-Silva, C. \& Ojcius, D. M. Ivermectin inhibits growth of Chlamydia trachomatis in epithelial cells. PLOS ONE 7, e48456 (2012).

102 Lim, L. E., Vilchèze, C., Ng, C., Jacobs, W. R. Jr, Ramón-García, S. \& Thompson, C. J Anthelmintic avermectins kill Mycobacterium tuberculosis, including multidrug resistant clinical strains. Antimicrob. Agents Chemother. 57, 1040-1046 (2013).

103 Ameen, S. M. \& Drancourt, M. Ivermectin lacks antituberculous activity. J. Antimicrob. Chemother. 68, 1936-1937 (2013).

104 Ramón-García, S. et al. Measurements of the in vitro anti-mycobacterial activity of ivermectin are method-dependent. J. Antimicrob. Chemother. 69, 1723-1724 (2014).

105 Omansen, T. F. et al. In-vitro activity of avermectins against Mycobacterium ulcerans. PLoS Negl. Trop. Dis. 9, e0003549 (2015).

106 Scherr, N., Pluschke, G., Thompson, C. J. \& Ramón-García, S. Selamectin is the avermectin with the best potential for Buruli Ulcer treatment. PLoS Negl. Trop. Dis. 9 e0003996 (2015).

107 Drinyaev, V. A. et al. Antitumor effect of avermectins. Eur. J. Pharmacol. 501, 19-23 (2004).

108 Driniaev, V. A. et al. Modification of antitumor effect of vincristine by natural avermectins. [In Russian]. Antibiot. Khimioter. 49, 3-5 (2004).

109 Lee, H., Kang, S. \& Kim, W. Drug repositioning for cancer therapy based on large-scale drug-induced transcriptional signatures. PLOS ONE 11, e0150460 (2016).

110 Hashimoto, H., Sudo, T., Maruta, H. \& Nishimura, R. The direct PAK1 inhibitor, TAT-PAK18, blocks preferentially the growth of human ovarian cancer cell lines in which PAK1 is abnormally activated by autophosphorylation at Thr 423. Drug Discov. Ther. 4, 1-4 (2010).

111 Dou, Q. et al. Ivermectin induces cytostatic autophagy by blocking the PAK1/Akt axis in breast cancer. Cancer Res. 76, 4457-4469 (2016).

$112 \mathrm{Kwon}, \mathrm{Y}$. J. et al. Selective inhibition of SIN3 co-repressor with avermectins as a novel therapeutic strategy in triple-negative breast cancer. Mol. Cancer. Ther. 14, 1824-1836 (2015)

113 Sharmeen, S. et al. The antiparasitic agent ivermectin induces chloride-dependent membrane hyperpolarization and cell death in leukemia cells. Blood 116, 3593-3603 (2010).

114 Shen, M. et al. Identification of therapeutic candidates for chronic lymphocytic leukemia from a library of approved drugs. PLOS ONE 8, e75252 (2013).

115 Furusawa, S. et al. Potentiation of doxorubicin-induced apoptosis of resistant mouse leukaemia cells by ivermectin. Pharm. Pharmacol. Commun. 6, 129-134 (2000).

116 Draganov, D. et al. Modulation of P2X4/P2X7/Pannexin-1 sensitivity to extracellular ATP via ivermectin induces a non-apoptotic and inflammatory form of cancer cell death. Sci. Rep. 10, 16222 (2015).

117 Melotti, A. et al. The river blindness drug ivermectin and related macrocyclic lactones inhibit WNT-TCF pathway responses in human cancer. EMBO Mol. Med. 6 , 1263-1278 (2014)

118 Ashraf, S. \& Prichard, R. Ivermectin exhibits potent anti-mitotic activity. Vet. Parasitol. 226, 1-4 (2016)

119 Tibbit, M. W., Dahlman, J. E. \& Langer, R. Emerging frontiers in drug delivery. J. Am Chem. Soc. 138, 704-717 (2016)

120 González, P., González, F. A. \& Ueno, K. Ivermectin in human medicine, an overview of the current status of its clinical applications. Curr. Pharm. Biotechnol. 13, 1103-1109 (2012).

121 N.d. Drugs for parasitic infections. Med. Lett. Drugs Ther. 143, e1-31 (2013).

122 Guzzo, C. A. et al. Safety, tolerability and pharmacokinetics of escalating high doses of ivermectin in healthy adult subjects. J. Clin. Pharmacol. 42, 1122-1133 (2002)

123 Gamboa, G. V. et al. Ivermectin-loaded lipid nanocapsules: toward the development of a new antiparasitic delivery system for veterinary applications. Parasitol. Res. 115, 1945-1953 (2016).

124 Clark, S. L., Crowley, A. J., Schmidt, P. G., Donoghue, A. R. \& Piché, C. A. Long-term delivery of ivermectin by use of poly(D,L-lactic-co-glycolic)acid microparticles in dogs. Am. J. Vet. Res. 65, 752-757 (2004).

125 Miller, A. J., Oehler, D. D. \& Pound, M. J. Delivery of ivermectin by injectable microspheres. J. Econ. Entomol. 91, 655-659 (1998).

126 Liu, X., Sun, Q., Wang, H., Zhang, L. \& Wang, J.-Y. Microspheres of corn protein, zein, for an ivermectin drug delivery system. Biomaterials 26, 109-115 (2005).

127 Ding, D., Sheng, X.-L., Liang, K.-X., Xu, Q. \& Liu, W. Study on ivermectin nanoemulsion for transdermal drug delivery. China Animal Husbandry Vet. Med. J. 42 401-407 (2015)

128 Chaccour, C. et al. Screening for an ivermectin slow-release formulation suitable for malaria vector control. Malar. J. 14, 102 (2015).

129 Miyajima, A. et al. Experimental study of pharmacokinetics of external, whole-body bathing application of ivermectin. J. Dermatol. 42, 87-89 (2015).

130 Yardley, M. M., Huynh, N., Rodgers, K. E., Alkana, R. L. \& Davies, D. L. Oral delivery of ivermectin using a fast dissolving oral film: implications for repurposing ivermectin as a pharmacotherapy for alcohol use disorder. Alcohol 49, 553-559 (2015) 


\section{APPENDIX 1}

\section{Current ivermectin usage}

Every year, more uses for the avermectins, and ivermectin in particular, are being found in human and animal health. Mectizan is the donated form of ivermectin manufactured by Merck \& Co. for use in human health, while Stromectol is the commercially available form. Besides donated ivermectin being the sole or primary tool in the two global disease elimination programs to conquer Onchocerciasis and Lymphatic filariasis, commercial preparations of ivermectin-based drugs are also being put to ever increasing uses.

Ivermectin (systemic) dosing regimens for the four 'official' target diseases and 10 so-called 'off-label' diseases are as follows:

1. Onchocerciasis (due to Onchocerca volvulus):

Oral: $150-200 \mu \mathrm{g} \mathrm{kg}^{-1}$ body weight as a single dose (optimal dose $=150 \mu \mathrm{g} \mathrm{kg}^{-1}$ ); retreatment may be required every $3-12$ months for 9-15 years until asymptomatic.

2. Lymphatic filariasis (due to Wuchereria bancrofti):

Oral: $150-200 \mu \mathrm{g} \mathrm{kg}^{-1}$ body weight (in combination with albendazole) twice annually or $300-400 \mu \mathrm{g} \mathrm{kg}^{-1}$ as a single dose annually.

3. Strongyloidiasis (due to Strongyloides stercoralis):

Oral: $200 \mu \mathrm{g} \mathrm{kg}^{-1}$ as a single dose; perform follow-up stool examinations.

Alternative dosing: $200 \mathrm{\mu g} \mathrm{kg}^{-1}$ per day for 2 days.

4. Scabies (due to Sarcoptes scabiei):

Oral: $200 \mu \mathrm{g} \mathrm{kg}^{-1}$ as a single dose (repeat dose in 7-14 days (for immunocompromised or immunocompetent patients).

Crusted scabies (Norwegian Scabies)

Oral: $200 \mu \mathrm{g} \mathrm{kg}^{-1}$ as a single dose on days $1,2,8,9$ and 15 in combination with topical permethrin $5 \%$ cream. Severe cases may require additional ivermectin treatment on days 22 and 29.

\section{'Off-Label' uses}

5. Pediculosis (due to Pediculus capitis, Pediculus corporis, Pediculus pubis):

Oral: Treatment generally requires $>1$ dose.

Pediculus humanus capitis: Oral: $400 \mu \mathrm{g} \mathrm{kg}^{-1}$ per dose every 7 days (2 doses).

Pediculus humanus corporis: Oral: $200 \mu \mathrm{g} \mathrm{kg}^{-1}$ per dose every 7 days (3 doses).

Pediculosis pubis: Oral: $250 \mu \mathrm{g} \mathrm{kg}{ }^{-1}$ dose every 7 days (2 doses) or $250 \mu \mathrm{g} \mathrm{kg}{ }^{-1}$ per dose every 14 days (2 doses).

6. Demodicosis (due to Demodex folliculorum and Demodex brevis):

Oral: $200 \mu \mathrm{g} \mathrm{kg}^{-1}$ as a single dose, followed by topical permethrin.

7. Blepharitis (due to Demodex folliculorum):

Oral: $200 \mu \mathrm{g} \mathrm{kg}^{-1}$ as a single dose, repeat dose once in 7 days.

8. Filariasis (due to Mansonella ozzardi):

Oral: $6 \mathrm{mg}$ as a single dose.

9. Filariasis (due to Mansonella streptocerca):

Oral: $150 \mu \mathrm{g} \mathrm{kg}^{-1}$ as a single dose.

10. Gnathostomiasis (due to Gnathostoma spinigerum):

Oral: $200 \mu \mathrm{g} \mathrm{kg}^{-1}$ as a single dose.

11. Cutaneous larva migrans (due to Ancylostoma braziliense):

Oral: $200 \mathrm{\mu g} \mathrm{kg}^{-1}$ as a single dose.

12. Trichuriasis (due to Trichuris trichiura):

Oral: $200 \mu \mathrm{g} \mathrm{kg}^{-1}$ as a single dose on day 1; may repeat dose on day 4 .

13. Ascariasis (due to Ascaris lumbricoides):

Oral: $200 \mathrm{\mu g} \mathrm{kg}^{-1}$ as a single dose.

14. Enterobiasis (due to Enterobius vermicularis):

Oral; $200 \mu \mathrm{g} \mathrm{kg}^{-1}$ single dose followed by second dose 10 days later.

(Data sources): ref. 120, (https://www.drugs.com/monograph/ivermectin.html\#r1) and refs 121, 122.

\section{APPENDIX 2}

Novel delivery systems for ivermectin

The oral route is the primary delivery mechanism for ivermectin, although it has been shown that liquid formulations provide twice the bioavailability.

Lipid nanocapsules have been prepared by a new phase inversion procedure and characterized in terms of size, surface potential, encapsulation efficiency and physical stability. An activation assay and uptake experiments by THP-1 macrophage cells were used to assess the 'stealth' characteristics of the nanocarrier in vitro. A pharmacokinetics and biodistribution study were also undertaken as a 'proof of concept' following subcutaneous injection in a rat model. The final ivermectin-lipid nanocapsules suspension had a narrow size distribution and an encapsulation rate $>90 \%$ constant over a 60 -day period. Flow cytometry and blood permanence confirmed the ability of these particles to avoid macrophage uptake. Moreover, the disposition of ivermectin in the subcutaneously administered lipid nanocapsules was higher compared to treatment with a commercial formulation, with no significant differences in the biodistribution pattern. This novel delivery system is a promising therapeutic approach in anti-parasitic control and may help delay the appearance of resistance. ${ }^{123}$

Poly(D,L-lactic-Co-glycolic) acid is a safe and effective biodegradable material and has been used as a drug delivery matrix for extended release applications. Results from experiments in pets and livestock indicate that poly(d,l-lactic-co-glycolic) acid containing ivermectin, either as 
microparticles or an injectable microsphere formulation, facilitated long-lasting delivery of the drug. ${ }^{124}$ The injectable microsphere formulation of ivermectin should be useful in a variety of other applications, including the control of external and internal parasites. ${ }^{125}$

In China, a novel microsphere drug delivery system of ivermectin using hydrophobic zein protein has been investigated. Releases of the drug from zein microspheres, tabletted microspheres and from pepsin degradation of tabletted microspheres were performed in vitro to investigate the mechanism of model drug release. The results indicate that the zein microspheres and tabletted microspheres are suitable for use as a sustained-release form of ivermectin. ${ }^{126}$

Another project developed an ivermectin nanoemulsion for investigation of transdermal drug delivery, whereby the physicochemical property, stability, in vitro drug release and transdermal property were all evaluated. The ivermectin nanoemulsion was stable when stored at $4{ }^{\circ} \mathrm{C}$ and at room temperature for 1 year. The cumulative permeation and retention of ivermectin nanoemulsion in $24 \mathrm{~h}$ were 3.24 and 2.05 times, respectively, more than commercially available preparations. These results indicated that the ivermectin nanoemulsion had the advantages of simple preparation process, excellent stability and efficacious transdermal delivery, and so had good application prospects. ${ }^{127}$

A range of serious challenges confronts the task of eliminating malaria, including emerging insecticide resistance in vector mosquitoes and by vectors with outdoor and/or nocturnal or crepuscular activity. Ivermectin has the potential to overcome such challenges by killing mosquitoes taking a blood feed, at any time, on animals and humans that have enough ivermectin in their blood following treatment. Unfortunately, a single oral dose generates only short-lived mosquitocidal plasma levels. To investigate the possibilities of increased mosquitocidal activity, three different slow-release formulations of ivermectin were tested to discover whether long-term mosquitocidal levels of ivermectin in the blood could be sustained for advantageous periods of time. All formulations steadily released ivermectin over a period of more than 12 weeks. Sustained plasma levels capable of killing 50\% of Anopheles gambiae feeding on a treated subject lasted for up to 24 weeks and no apparent adverse effects attributable to the drug were identified. Modeling predicts a $98 \%$ reduction in infectious vector density based on an ivermectin formulation with a 12-week drug release duration. These results indicate that relatively stable mosquitocidal plasma levels of ivermectin can be safely sustained for up to 6 months using a silicone-based subcutaneous formulation, such that modifying the formulation of ivermectin could be a suitable strategy for malaria vector control. ${ }^{128}$

As a novel method aimed at improving the safety of conventional oral ivermectin for scabies treatment, a 'whole-body bathing method' was conceived. In this method, patients bathe themselves in a fluid containing ivermectin at an effective concentration. Measurement of ivermectin concentration in the skin and plasma after bathing rats in a fluid containing $100 \mathrm{ng} \mathrm{ml}{ }^{-1}$ of ivermectin, found the concentration of ivermectin was clearly higher than that measured in patients taking ivermectin by mouth. Consequently, the method would be a preferable drug delivery system for topical skin application of ivermectin compared with administration per os. ${ }^{129}$ A similar initiative found that the use of another promising alternative dosage form, namely fast-dissolving oral films, worked well with ivermectin. ${ }^{130}$ 